\title{
Development and Exploitation Countermeasures of Hubei National Sports Tourism
}

\author{
Wu Zhong \\ Physical Education School \\ Wuhan Business University \\ Wuhan, China \\ 7849800@qq.com
}

\author{
Song Cai-yun \\ Physical Education School \\ Wuhan Business University \\ Wuhan, China
}

\begin{abstract}
In recent years, sports tourism industry is becoming more and more prosperous. As a special sports tourism project, national sports tourism has huge market potential and can bring economic benefits. By means of survey method, logical analysis method and literature material method, this paper discusses the present situation of national sports tourism in Hubei province, and puts forward reasonable suggestions and measures for the development of ethnic sports tourism, aiming to excavate resources that are conducive to national sports tourism, mobilize the enthusiasm of the development of ethnic sports tourism industry, create a new economic growth driver, and further promote the economic development in Hubei province.
\end{abstract}

Keywords-National sports; Tourism industry; Development; Measure

\section{INTRODUCTION}

With the development of economy and improvement of society, people's economic capabilities have been increasingly strengthened, and the pursuit of leisure is gradually increasing. Tourism, as a rapidly booming industry, has immeasurable market potential and economic benefits. Recent developments in sports tourism, such as rafting and mountaineering, have become prevalent national sports tourism integrates nationality, cultural entertainment, and skills. It has become a rising tourism industry with important historical and practical significance. Hubei Province is a multi-national and multipopulation province with convenient transportation, rich traditional sports tourism resources and excellent geographical conditions. However, due to the low prevalence of national sports tourism in China. People lack understanding of national sports tourism and have not formed a series of professional management systems. To a certain extent, it restricts the development of the Hubei national sports tourism industry. How to effectively integrate Hubei sports tourism resources and establish a scientific management system is the key to promoting the development of national sports tourism.

\section{CURRENT SituAtion OF DEVELOPMENT OF NATIONAL SPORTS TOURISM}

\section{A. Traditional Business model}

Hubei Province is not only a province with a large population but also a multi-ethnic province. There are many ethnic minorities such as Tujia, Miao, Hui, Dong, Zhuang and Manchu. Most of them are located in ethnic autonomous areas in southwestern Hubei, and some of them live in places such as Wuhan and Jingzhou. Different regions have distinctive ethnic cultural features and strong humanistic customs.

Through the review of existing literature data, characteristic projects in Hubei Province include: Wrestling of Yichang Ergui, "Dragon Dance" of Zhuang, Dragon Boat Race of Jingzhou, "Hand Dancing" of Enshi Tujia, "Jiao Lusheng" of Miao, and Chibi Hui's "Wooden Balls", etc. They are very famous ethnic sports tourism projects. Every year when they are held, they will attract a large number of domestic and foreign tourists. All of them are highly ornamental and entertaining, but most of them have shortcomings such as limited activity cycle, strong skills, and low participation of ordinary tourists.

\section{B. Feasibility of Development of National Sports Tourism in Hubei Province}

1) The Economic Base for Developing Ethnic Sports Tourism in Hubei Province

With the concept of "Central China Rising" proposed, Wuhan, as a central city in the middle of the country, has witnessed rapid development in its economic development and urban construction. The urban circle economy formed around Yichang, Huangshi, and Ezhou also shows an upward trend. According to the latest "2016-2020 County Economic Development Plan" issued by the Hubei Economic and Information Commission, 10 suburban counties of Hubei Province has officially entered the 50 billion. Daye is a famous city in China. Qianjiang is famous for Jianghan Oilfield, Shanghai-Chengdu Expressway and Beijing-Guangzhou Railway. It is rich in mineral resources and hydropower resources. It can be seen that Hubei Province enjoys a strong overall economic development advantage. Enshi, Yichang and other cities where ethnic minorities live in large numbers have 
stressed the need to vigorously develop the tourism industry as early as in the "the Eleventh Five-Year Plan" of Hubei. Today, the economic development of the "the Belt and the Road" is remarkable. Hubei Province, which is in the Yangtze River Economic Belt, has plenty of opportunities for economic development. The national sports tourism, a new innovative industry, has great economic potential for development in Hubei Province.

\section{2) Policy Support for the Development of Nation Sports} Tourism in Hubei Province

In 2014, the State Council issued a number of opinions on promoting the reform and development of the tourism industry - actively developing leisure and holiday tourism, accelerating the construction of sports tourism facilities, and effectively promoting the integration of tourism and leisure. In 2016, the Hubei Provincial People's Government has issued a detailed circular on the development of the "13th Five-Year Plan" for the development of eco-cultural tourism in western Hubei: 1) To promote the innovation and development of industrial culture - develop new business models, focusing on industries in key industries such as tourism and sports, accelerating the development of new industries, and enhancing the core competitiveness of the industry; 2)To develop key areas of featured cultural industries - creating distinctive cultural industries, Strengthening overall planning, innovating industrial mechanisms, and promoting the coordinated development of regional cultural industries; 3) To strengthen the promotion of tourism image - with the guidance of "delicately beautiful Hubei and Charmful Hubei", highlighting the unique quality of Hubei folk cultural tourism and planing the brand image [4]. These policies all indicate that both the State Council and the Hubei Provincial Government have supported the cultural tourism of Hubei Province in Hubei Province. This provides a good policy environment for national sports tourism in folk culture tourism.

3) The cultural requirements for the development of national sports tourism in Hubei Province

Hubei Province is a multi-ethnic province. The population of ethnic minorities in the province accounts for $4.68 \%$ of the total population of the province. The geographical area of the autonomous region accounts for $1 / 6$ of the total area of the province. Nine out of 10 counties and cities in Hubei autonomous areas are classified as national key povertystricken counties. These data clearly show that the development of ethnic minority areas is an important part of the overall development of Hubei Province. Nowadays, the cities in the Wuhan Economic Circle in Hubei Province are developing rapidly. The industrial and electronic industries are developing rapidly and bring huge economic benefits. However, ethnic minorities live in the Lushan Basin where the transportation is relatively inconvenient. Most of them make a living by relying on agriculture and service industries, and economic development is relatively slow. Creating a new type of emerging industry, stimulating economic vitality and expanding domestic demand consumption are the urgent needs for the development of local ethnic minority areas. It focuses on tourism and combines local ethnic characteristics to develop new national sports tourism industries. It promotes the local economy, increases the income of the local minority people, and helps to improve people's living standards. This not only enables our country's precious folk culture to be effectively inherited and developed, but also realizes the sustenance of ethnic minorities for ethnic minorities. This is also of great significance to our national unity and social stability.

\section{THE CONSTRAINTS OF THE DEVELOPMENT OF NATIONAL SPORTS TOURISM}

\section{A. Impact of foreign sports culture}

With the development of the Olympic Games, the competitive sports further penetrated the hearts of the people. Most people are more concerned about the ornamental value and commercial value brought by competitive sports. National sports are only loved by a few people. Moreover, the development of sports in foreign countries is relatively mature and has a relatively large scale. Many sports-related industries in China draw lessons from foreign sports development models. The development of modern sports in the city, such as fitness clubs, football clubs, etc., has also formed a kind of learning style advocating competitive sports in the society. Many parents send their children to practice badminton, table tennis, and aerobics when they are young. This has restricted the development of national sports.

\section{B. The slow overall economic development in areas where ethnic minorities living together}

At present, the tourist industry in Hubei, Southwest, and other minority areas is more developed. However, the overall local planning is weak, economic development is slow, and there is no leading pillar industry. The project is much the same, and the industrial structure needs to be optimized. Because of its rugged terrain, it is necessary to build a special national sports township, a special ethnic sports tourism village, etc. The road to traffic has been limited, and the infrastructure for ethnic sports is relatively backward.

\section{The imperfect laws and regulations on national sports tourism}

At present, ethnic sports tourism has not yet established independent administrative departments, but only national cultural administrations, sports bureaus, tourism bureaus, etc. There is no sound system, which has led to overlapping of many functional departments and wasted resources. Some related travel management agencies are asking for prices. The poor quality of tourism products leads to poor tourist experience. Travel agencies do not have uniform and standardized management, and there is a tendency for vicious competition and monopolyism among related industries.

\section{People's weak awareness about the industrial culture of ethnic sports tourism}

According to surveys, people in ethnic minorities have deep feelings about the original folk culture, national style, and national sports connotation, but they are very different from modern people's concepts of tourism culture, aesthetic characteristics and value orientation. In terms of tourism products, it only stays above the view of entertainment and 
entertainment. It does not actively integrate tourists into characteristic ethnic sports. This reduces the participation of tourists and affects the value of their sensory experience. This has caused certain adverse effects on the development of national sports tourism.

\section{E. The lack of professionals specializing in the management of ethnic sports tourism industry}

At present, "tourism + sports" is still in the initial stage of development. The unique national sports tourism talents are treasures. The survey found that most of the personnel involved in sports tourism participate in the training of social organizations. There is no corresponding organizational guidance and specialized college education, and their professional qualities and service attitudes need to be improved.

\section{THE DEVELOPMENT OF ETHNIC SPORTS TOURISM IDEAS AND DEVELOPMENT STRATEGIES}

\section{A. Deepening the reform of economic development strategy}

\section{1) Developing national sports tourism new industries}

The economic development of the Wuhan city circle and the leading role of the central city can be used to create opportunities, strengthen horizontal linkages and economic cooperation with all sectors of society and related industries. By doing so, it can achieve coordinated development and resource sharing of the regional economy. By adopting the principle of "Anyone who invest will benefit", we can actively integrate into the characteristics of the socialist market and create a new economic and industrial chain. A national sports tourism circle focusing on the western Hubei circle can be formed. A fine-quality ethnic sports tourism project can be established, a national sports tourism theme park can be established, and brands can be promoted. National culture connotations can be comprehensively utilized, and innovative ethnic sports tourism products can be developed.

\section{2) Innovating the business model}

According to the consumer's different consumer psychology, aesthetic cultural level and artistic accomplishment, the national sports tourism area is created in different levels, and high-end customization is introduced. For example, today's more popular corporate executive meditation and learning Taichi are all aimed at relaxing the mind and body through ethnic sports and other folklore projects. This kind of tourist area that is different from other places can satisfy people's different consumer needs at all levels.

\section{3) Rationally integrating provincial resources}

There are many historical sites in Hubei Province, which have profound historical and cultural heritage. Ethnic sports tourism can be based on historical and cultural carriers, based on actual and reasonable overall planning, the development of characteristic historical and cultural products and historical ethnic sports experience areas. Combining commemorative and ornamental real products with tourists' favorite and participatory experience products to achieve an industrial structure with diversified investment structure and diversified development forms, it gradually enters the new normal of Hubei economic development.

\section{B. Effectively implementing the government's support policy}

(1)The national sports tourism mechanism should be established and improved. An independent national sports tourism department should be established. It should simplify government functions, strengthen government management, and formulate policies for the development of national sports tourism industry. It should improve the laws and regulations of national sports tourism, and include the development of national sports tourism Government performance, and improve the enthusiasm of the relevant government personnel.

(2)It should strengthen the unified management of national sports tourism travel agencies, improve the consumer protection system for tourists, strengthen the functions of travel agencies, and encourage travel agencies to innovate their marketing models. It should cooperate with related industries such as Tueniu, Ctrip, etc., travel websites such as Didi Express, Alipay and other payment software. This can fully optimize the tourist route, increase the cost performance and meet the actual needs of tourists; it should contact the relevant government departments, strengthen cooperation with foreign travel agencies, and fully increase the national sports tourism advertising.

(3)It should strengthen the exchange and interaction of sports professionals. The development of the country affects the development of all regions of the country. Therefore, government departments should always pay attention to the dynamics of the country and give strong support to the training of sports personnel.

\section{Diversifying innovative propaganda models and promoting the publicity}

It can make use of the development of modern multimedia, make full use of "Internet + " technology, research and development of APP focused on national sports tourism, create a self-operated Weibo or WeChat public platform, establish a unique travel website; Together with CCTV, Hubei TV stations, tourism TV and other TV cooperation, in the iQIYI, Youku and other website video on the theme of national sports tourism promotional film or micro-film, etc., it increases advertising efforts.

At the same time, it regularly collaborates with domestic and foreign travel magazines or periodicals to create national sports tourism columns; produce books, brochures, or postcards.

It can attract people's attention by organizing national sports games, encourage competition system, and encourage wide participation of the public; it can establish primary and secondary school students sports experience tour, deepen cooperation with the school's propaganda, and raise people's awareness of national sports tourism industry. 


\section{Focusing on training professionals in national sports tourism}

(1)It should strengthen the links between colleges and universities in Hubei Province. National sports tourism courses in sports colleges should be set up and it should increase ethnic sports tourism majors, and train specialized senior management talents for national sports tourism; In addition, schools should pay attention to cultivating students' sense of national culture identity. The self-esteem and self-confidence of ethnic cultures should be enhanced, thereby stimulating students' enthusiasm for learning about national sports tourism.

(2)It should actively study foreign national sports management models, learn advanced management experience, take its essence, and further promote the development of national sports tourism in the direction of specialization, industrialization, and internationalization.

\section{E. Focusing on ecology and respect for folk customs}

Focusing on the combination of ecological and economic benefits, we must follow the principle of sustainable development and adopt the policy of "development and protection progress" when integrating and planning ethnic sports tourism resources. We must also respect the folk culture of ethnic minorities when developing national sports tourism. Some traditional taboos may violate language or behavior. Visitors may set up publicity columns at tourist attractions to inform other tourists so as to avoid unnecessary misunderstandings affecting the feelings of various ethnic groups.

\section{CONCLUSION}

In summary, the development of national sports tourism can not only ease the pressure on employment in society, but also promote the economic development of Hubei Province. More importantly, it can improve poverty in some ethnic minority areas, promote national unity, and safeguard national stability. To develop ethnic sports tourism, we must combine the comprehensive resources and actual conditions of Hubei Province, optimize the structure of the national sports tourism industry, and strive to upgrade the national sports tourism products with excellent quality and build an independent brand for national sports tourism. We should develop leading enterprises in the development of national sports tourism, increase social employment opportunities, and cultivate new talents. This is conducive to national unity and mutual assistance, social harmony and stability. It can help achieve new economic growth in Hubei Province, and promote the further prosperity and development of Hubei Province's economy.

\section{ACKNOWLEDGMENT}

This work has been funded by the Colleges and Universities Outstanding Youth and Middle Aged Scientific and Technological Innovation Team Project of Hubei Province (No.T201628).

\section{REFERENCES}

[1] Luan Lixia, Guo Juan. A Study on the Traditional Sports Tourism Market of Ethnic Minorities in Hubei Province [J]. Beijing: Journal of Xi'an Institute of Physical Education, 2006(2):58-60.

[2] Liu Lina. Research on causes of poverty and poverty alleviation policy in Hubei ethnic minority areas [D]. Wuhan: South-Central University for Nationalities, 2012.

[3] Zhou Qing. Exploration of the Mode of Leisure and Holiday Tourism Leading the Construction of Shangrao's Strong Tourist City [J]. Journal of Hubei University of Economics (Humanities and Social Sciences), 2016, (1): 44-45.

[4] Hubei Provincial Government. Eco-Cultural Tourism Circle in Western Hubei "13th Five-Year Plan" [EB/OL]. Http:// www.Inic.cn/ ljw/ hgjj /zcdt /2017/ 01/ 436306.shtml

[5] Jia Shuyuan. Research on Economic Development of Ethnic Minorities in Hubei Province [J]. China, 2011, (2): 140-140.

[6] Hong Gang. Research on Curriculum Design of Sports Tourism in Colleges and Universities [D]. Liaoning Normal University, 2013.

[7] Zhang Xinyi. The status quo, the causes and the path of the development of the national traditional sports in colleges and universities. [J]. Sports, 2014, (19): 65-66, 90. 